\title{
How do common chronic conditions affect health-related quality of life?
}

\author{
Isobel TM Heyworth, Michelle L Hazell, Mary F Linehan and Timothy L Frank
}

\begin{abstract}
Background

Comorbidity is common. National Institute for Health and Clinical Excellence (NICE) guidelines have been created to make best use of resources to improve patients' quality of life but do not currently take account of comorbidity. The effect of multiple chronic conditions with regard to health-related quality of life (HRQoL) is poorly researched. Criticisms of previous research have been due to patient-defined chronic conditions, lack of quantification of the effects of confounding factors, selection of affected patients only, small sample sizes, and upper age limits.
\end{abstract}

Aim

This study aims to address these issues, looking into the impact of combinations of chronic conditions on HRQoL.

\section{Design of the study}

Participants filled in a questionnaire containing general health information, specific respiratory questions, and the EQ-5D measure of HRQoL. The questionnaires were then matched up to their GP records to obtain their disease status for six common chronic diseases (asthma, chronic obstructive pulmonary disease, ischaemic heart disease, hypertension, diabetes, and cerebrovascular disease).

\section{Method}

Data from a mailed questionnaire were analysed from 5169 patients aged $>16$ years from two general practices in Wythenshawe, Manchester in 2004. Completion of the questionnaire was taken to indicate consent to participate.

\section{Results}

Significant correlations were found between a lower $\mathrm{HRQOL}$ and increasing numbers of chronic conditions $(P<0.001)$, increasing age, possible obstructive airway disease, lack of higher education, smoking, and female sex. These all remained significant following regression, except for sex, with number of chronic conditions being a strong predictor of the weighted health state index score, EQ-5D index (coefficient $=-0.079, P<0.001$ ).

\section{Conclusion}

Increasing numbers of chronic conditions have a strong negative effect on HRQoL.

Keywords

chronic disease; comorbidity; EQ-5D; health related quality of life.

\section{INTRODUCTION}

Improvements in living conditions, together with advances in medical science, have led to an increased number of patients living with chronic conditions. Studies indicate that comorbidity is the normal state of affairs, especially in patients aged $>65$ years, ${ }^{1}$ and $50 \%$ of patients with a chronic disease have more than one. ${ }^{2}$ Within the UK healthcare system, there has therefore been a shift in the way in which patients are treated, evidenced by the Department of Health recognising the importance of long-term conditions, ${ }^{3}$ and by The Royal College of General Practitioners including the ability to provide person-centered care as a core competence for GPs. ${ }^{3,4}$ This, in addition to numerous choices in treatments and the limitations of a publicly funded health service, has made quality of life measurement a hugely relevant issue in 2009.

Priorities in health care must be set, and it is now generally accepted that one of the most important considerations should be the improvement in patients' health-related quality of life (HRQoL) with a treatment, ${ }^{5,6}$ rather than relying solely on change measured from the healthcare professional's perspective. A single HRQoL value in conjunction with cost and distribution issues could be key to choosing

ITM Heyworth, $M B C h B$, foundation year 2 trainee in general practice; ML Hazell, $P h D, M B C h B$, honorary research associate; MF Linehan, BSc(Hons), PhD, RGN, honorary research associate; TL Frank, MD, FRCGP, honorary reader and GP principal, Faculty of Medical and Human Sciences University of Manchester, Manchester.

Address for correspondence

Timothy Frank, North West Lung Research Centre, University of Manchester, General Practice Research Unit, GP Research Unit, North West Lung Research Centre, Wythenshawe Hospital, Southmoor Road,

Manchester, M23 9LT.

E-mail: timothy.frank@manchester.ac.uk

Submitted: 22 October 2008; Editor's response: 12 December 2008; final acceptance: 29 January 2009. (C) British Journal of General Practice

This is a full-length article of an abridged version published in print and originally published online first on 24 July 2009. Cite this version as: Br J Gen Pract 2009 DOI: 10.3399/bjgp09X453990 (abridged text, in print: Br J Gen Pract 2009; 59: 833-838). 
fairly between different treatments and interventions. However, since values created by patients compared to those created by the non-affected populations differ, ${ }^{5}$ intense debate continues over how to balance the HRQoL values into such a figure. ${ }^{7,8}$

Several papers comparing quality of life measurement tools ${ }^{9-11}$ have agreed that perhaps the most appropriate tool across the board is the EQ-5D. ${ }^{12}$ This is a generic HRQoL measure which, in contrast to disease-specific instruments, can compare HRQoL in populations, regardless of disease. The EQ-5D consists of two parts; the first part records selfassessed health status according to five dimensions: mobility, self-care, usual activities, pain/discomfort, and anxiety/depression. Each dimension is divided into three levels: no problem, some problems, and severe problems. A unique health state can be expressed by combining the different level from each dimension. This is then transformed into a weighted health state index score $\left(E Q-5 D_{\text {index }}\right)$, using a tariff of values derived from valuation exercises carried out in general populations. ${ }^{13}$ The second part records the responders' overall assessment of their health on a $20 \mathrm{~cm}$ visual analogue scale (EQ 5D vas). In both cases, a larger number represents better HRQoL. Using information from the EQ-5D, judgments can also be made about the most efficient way to use available resources in order to improve the health of the population. EQ-5Dindex is considered by the National Institute for Health and Clinical Excellence (NICE) to be the most appropriate method for providing utility values of health states. ${ }^{14}$

Despite this advancement in measuring quality of life, research has poorly represented combinations of chronic conditions. The papers that do exist have tended to focus on a single chronic disease, for example chronic obstructive pulmonary disease (COPD) ${ }^{15}$ or diabetes, ${ }^{16}$ yet practical observation indicates that such patients often suffer with multiple problems. ${ }^{17,18}$ Even the existing and widely used reference values for EQ-5D in the UK do not currently take account of comorbidity. ${ }^{19}$ Fortin et al concluded in 2005 that, to date, the number and diversity of articles on comorbidity are both insufficient to provide scientific background for strong evidence-based care of patients affected by multiple concurrent chronic conditions, and that the deficit in research is particularly marked within the primary care setting. ${ }^{20}$

This paper addresses this gap in knowledge by examining the impact of the combinations of common chronic conditions on HRQoL.

\section{METHOD}

In the UK, patients register with one GP in order to access NHS facilities. Practices keep records of consultations, diagnoses, and prescriptions and these

\section{How this fits in}

This paper adds information collected from a primary care setting relating to how health-related quality of life is adversely affected by increasing numbers of chronic conditions.

records go with a patient if they move to another practice. All patients registered with either of two general practices were invited to take part in a postal survey in 2004. The survey asked about specific respiratory problems as well as general health details, and included the EQ-5D questionnaire about HRQoL. Return of the questionnaires was taken to indicate consent, but recipients were also given the opportunity to opt out of having their responses matched with information from their general practice notes. Diagnostic status at the time of the survey for each of six common conditions (asthma, COPD, ischaemic heart disease, hypertensive disease, diabetes mellitus, and cerebrovascular disease) were obtained from general practice records for those who had not opted out. Where disease registers were held by the practice, these were used to determine diagnostic status. These registers are generated by the general practice to include patients whose records contain designated episode or treatment codes (Read codes). Where no formal disease register was kept, data were obtained from relevant individual Read codes. The HRQoL results were then linked to diagnostic status at the time the EQ-5D questionnaire was completed, thereby allowing contemporaneous comparison of results by comorbidity.

Statistical analysis was conducted using the computer software program SPSS (version 15, SPSS Inc, 2006). $\chi^{2}$ values were calculated for the exploration of differences in proportions, Student $t$ tests for differences in HRQoL means, and linear regression analysis to correct for confounding factors. Values of $P<0.05$ were taken to indicate statistical significance.

\section{RESULTS}

\section{Participation}

Of the 11020 individuals included in the postal survey, $5169(46.9 \%)$ responded, and of these 333 (6.4\%) opted out of the matching with medical records data that followed. Statistical analyses were conducted to check that these opt outs were not a distinct group that would consequently be under-represented within the data. The results showed that overall there was no difference between opt outs and those included in the main analyses with regard to sex, smoking, or passive smoking (Table 1). There were, however, several differences that built up an interesting picture of the people more likely to opt out. 
Table 1. Characteristics of individuals by decision to opt out of disease register analyses with significance levels for $t$-tests of differences in means and $\chi^{2}$ tests of differences in proportions.

\begin{tabular}{lccc} 
& Opted out $(n=333)$ & Opted in $(n=4836)$ & $P$-value \\
\hline Mean age, years (SD) & $50.9(20.2)$ & $47.9(21.2)$ & $<0.001$ \\
\hline Female, \% $(n)$ & $59.5(194 / 326)$ & $54.9(2595 / 4729)$ & 0.100 \\
\hline Smokers, \% $(n)$ & $36.4(91 / 250)$ & $37.6(1402 / 3727$ & 0.700 \\
\hline $\begin{array}{l}\text { Exposed to passive } \\
\text { smoke at home, \% }(n)\end{array}$ & $35.7(85 / 238)$ & $38.5(1440 / 3738)$ & 0.390 \\
\hline Higher education, \% $(n)$ & $28.9(95 / 329)$ & $37.7(1801 / 4773)$ & 0.001 \\
\hline Seeking work, \% $(n)$ & $3.8(12 / 316)$ & $2.3(103 / 4558)$ & 0.080 \\
\hline EQ-5D problems, \% $(n):$ & & & \\
Mobility & $29.7(94 / 316)$ & $31.3(1478 / 4722)$ & 0.560 \\
Self-care & $14.3(45 / 314)$ & $12.5(583 / 4658)$ & 0.350 \\
Usual activities & $31.8(101 / 318)$ & $31.0(1461 / 4717)$ & 0.770 \\
Pain/discomfort & $46.4(148 / 319)$ & $47.5(2231 / 4695)$ & 0.700 \\
Anxiety/depression & $42.4(133 / 314)$ & $35.2(1646 / 4671)$ & 0.010 \\
\hline EQ-5Dindex, mean (SD) & $0.8(0.3)$ & $0.8(0.3)$ & 0.940 \\
\hline EQ-5Dvas, mean (SD) & $73.8(19.8)$ & $70.9(19.8)$ & 0.010 \\
\hline
\end{tabular}

Table 2. Characteristics of chronic disease groups within the study.

\begin{tabular}{lcccccc} 
& $\begin{array}{c}\text { Asthma } \\
(n=429)\end{array}$ & $\begin{array}{c}\text { COPD } \\
(n=280)\end{array}$ & $\begin{array}{c}\text { Diabetes } \\
(n=348)\end{array}$ & $\begin{array}{c}\text { Hypertension } \\
(n=1201)\end{array}$ & $\begin{array}{c}\text { IHD } \\
(n=442)\end{array}$ & $\begin{array}{c}\text { Stroke } \\
(n=101)\end{array}$ \\
\hline $\begin{array}{l}\text { \% those who } \\
\text { had }>1 \text { chronic } \\
\text { disease }(n=1902)\end{array}$ & 14.7 & 18.3 & 63.1 & 23.2 & 5.3 \\
\hline $\begin{array}{l}\% \text { questionnaire } 8.3 \\
\text { responders } \\
(n=5169)\end{array}$ & 5.4 & 6.7 & 23.2 & 8.6 & 2.0 \\
\hline $\begin{array}{l}\text { EQ-5Dindex, } \\
\text { mean (SD) }\end{array}$ & $0.67(0.34)$ & $0.53(0.35)$ & $0.62(0.34)$ & $0.65(0.32)$ & $0.55(0.34)$ & $0.49(0.36)$ \\
\hline $\begin{array}{l}\text { EQ-5D } 5 \text { vas, } \\
\text { mean (SD) }\end{array}$ & $65.5(22.3)$ & $57.5(19.8)$ & $63.8(20.4)$ & $67.1(19.8)$ & $61.0(20.0)$ & $57.4(21.3)$ \\
\hline
\end{tabular}

$C O P D=$ chronic obstructive pulmonary disease. $I H D=$ ischaemic heart disease.

Table 3. Variations in health-related quality of life by baseline characteristics with significance levels for $t$-tests of differences in means.

\begin{tabular}{lcccc} 
& Mean (SD) EQ 5D index & $P$-value & Mean (SD) EQ-5D vas & $P$-value \\
\hline Sex & & & & \\
$\quad$ Female & $0.75(0.30)$ & 0.003 & $73.0(20.2)$ & 0.007 \\
Male & $0.78(0.29)$ & & $74.6(19.2)$ & \\
\hline Smoker & & & & \\
$\quad$ No & $0.78(0.28)$ & $<0.001$ & $75.0(19.5)$ & $<0.001$ \\
Yes & $0.73(0.32)$ & & $70.4(20.1)$ & \\
\hline $\begin{array}{l}\text { Passive smoker } \\
\text { Yes }\end{array}$ & $0.78(0.28)$ & 0.96 & $74.4(19.3)$ & 0.27 \\
No & $0.7(0.29)$ & & $75.1(19.3)$ & \\
\hline Higher education & & & & \\
Yes & $0.83(0.25)$ & $<0.001$ & $77.9(18.3)$ & $<0.001$ \\
No & $0.72(0.32)$ & & $70.9(20.2)$ & \\
\hline
\end{tabular}

Individuals who opted out were older (mean (standard deviation, [SD]) age 50.9 years (20.2) versus $47.9(21.2)$ years, $P<0.001)$ and significantly less likely to have higher education than those who opted in (28.9\% [95] versus $37.7 \%$ [1801, $P$ for $\chi^{2}$ test $=0.001])$. They were also more likely to have reported problems on the anxiety/depression domain of the EQ-5D (42.4\% [133] versus 35.2\% [1646], $P=$ 0.011 ), but all the other domain questions showed equality between the two groups (Table 1). EQ-5Dindex showed no significant difference between the groups; however, people who opted out had a significantly lower EQ-5D vas value (mean [SD] of 70.9 years [19.8] compared to 73.8 years [19.8], $P=$ 0.014) (Table1).

\section{Main analyses}

The main analyses showed that hypertension was by far the highest represented chronic condition as well as having the highest $E Q-5 D_{\text {index }} / E Q-5 D_{\text {vas }}$ results (Table 2). The least common chronic condition was stroke, while the lowest $E Q-5 D_{\text {index }} / E Q-5 D_{\text {vas }}$ values were seen in COPD (Table 2).

A decrease in $E Q-5 D_{\text {index }}$ and $E Q-5 D_{\text {vas }}$ with age was highly significant $(P<0.001)$ in the study results (Pearson correlation coefficient $=-0.33$ for $E Q-5 D_{\text {index }}$ and -0.29 for EQ-5Dvas). Significantly lower values of HRQoL on both EQ-5D index and EQ-5D vas were associated with female sex, smoking, and absence of higher education. Higher education showed the greatest impact. No significant difference was seen with passive smoke exposure (responder reports of other adults in the home who smoke) (Table 3).

The values for $E Q_{\text {index }}$ and $E Q_{\text {vas }}$ showed a highly significant $(P<0.001)$ decrease with increasing number of chronic conditions (Spearman rank correlation coefficient for $E Q-5 D_{\text {index }}=-0.342$ and for $\left.E Q-5 D_{\text {vas }}=-0.332\right)$. There appeared to be a consistent decrease in quality of life value with each added chronic disease (Table 4 and Figures 1 and 2).

A stepwise linear regression analysis of number of chronic conditions, age, sex, smoking status, and continued education (probability to enter, <0.05; probability to remove, $>0.1$ ), with $E Q-5 D_{\text {index }} / E Q-5 D_{\text {vas }}$ as the dependent variable, identified that this correlation was still significant following the consideration of confounding factors $(P<0.001)$. It also demonstrated that the total number of chronic conditions was an important factor in relation to both EQ-5D index and EQ-5D vas (coefficients $-0.079, P<0.001$ and $-5.914, P<0.001$ respectively), although smoking was associated with the largest effects (Table 5). Breaking down the EQ-5Dindex into its component dimensions showed that problems in all five dimensions became more common with increasing numbers of chronic conditions (Table 6). 
Table 4. Health-related quality of life by number of chronic diseases.

\begin{tabular}{lccccc}
$\begin{array}{l}\text { Chronic } \\
\text { diseases, } n\end{array}$ & Individuals, $n$ & $\begin{array}{c}\text { EQ-5Dindex } \\
\text { Mean (SD) }\end{array}$ & $95 \% \mathrm{Cl}$ & $\begin{array}{c}\text { EQ-5D vas } \\
\text { Mean (SD) }\end{array}$ & $95 \% \mathrm{Cl}$ \\
\hline 0 & 2934 & $0.83(0.25)$ & 0.82 to 0.84 & $78.6(17.9)$ & 77.9 to 79.3 \\
\hline 1 & 1209 & $0.69(0.32)$ & 0.67 to 0.71 & $69.4(19.7)$ & 68.2 to 70.6 \\
\hline 2 & 510 & $0.61(0.33)$ & 0.58 to 0.64 & $63.3(19.0)$ & 61.6 to 65.0 \\
\hline 3 & 164 & $0.50(0.37)$ & 0.44 to 0.56 & $56.7(21.9)$ & 53.2 to 60.3 \\
\hline 4 & 15 & $0.39(0.32)$ & 0.22 to 0.57 & $40.7(16.6)$ & 30.2 to 51.1 \\
\hline 5 & 4 & $0.25(0.36)$ & -0.33 to 0.83 & $39.2(7.0)$ & 28.1 to 50.4 \\
\hline
\end{tabular}

\section{DISCUSSION}

\section{Summary of main findings}

The study results show that HRQoL declined significantly and consistently with an increasing number of chronic conditions and that this decline persisted following correction for confounding factors. The comparatively small number of studies that have also looked into the issue seem to support this observation, ${ }^{20}$ although there are some differences. Wee et al demonstrated that individuals with diabetes had a decreasing HRQoL with comorbid hypertension, heart disease, or musculoskeletal illness. ${ }^{21}$ Their study did, however, also show an increasing and synergistic HRQoL value with comorbid heart disease. ${ }^{21}$ Fortin et al showed that chronic vascular, upper gastrointestinal and musculoskeletal conditions also correlated with a drop in HRQoL, including a synergistic negative effect between respiratory and cardiac complaints. ${ }^{22}$ This previously reported link, ${ }^{23,24}$ thought to be due to inflammatory markers, might go some way to explaining the effects of COPD seen in the present study.

\section{Strengths and limitations of the study}

Generally, current research supports the negative correlation between number of chronic conditions and HRQoL. ${ }^{16,22,23,25}$ No direct comparisons can be made due to the extremely small number of studies and lack of comparable methods. As the present study used healthcare professionals' determination of chronic condition status, it is of considerable interest within a field that is often criticised for using patientdetermined chronic condition status. ${ }^{26}$ GPs are more likely than patients to use standardised diagnostic criteria, making the results more accurate. It avoids other criticisms by having a comparatively large sample size and correcting for confounding factors, ${ }^{26}$ and represents both healthy and affected individuals with no upper age limit.

It is important to point out, however, that within the study sample, numbers of patients with each added disease dwindled to just four patients with five chronic conditions, and there were no patients with the full six conditions. Nevertheless, this link between HRQoL and number of chronic conditions has not been widely observed before and has implications for clinical practice.

Factors influencing the decision to opt out among the study sample must be considered. Absence of higher education might be associated with a lack of awareness as to what research may entail, and the reporting of anxiety and depression might be linked to

Figure 1. Graph to show mean EQ-5D $D_{\text {index }}$ with increasing number of chronic conditions.

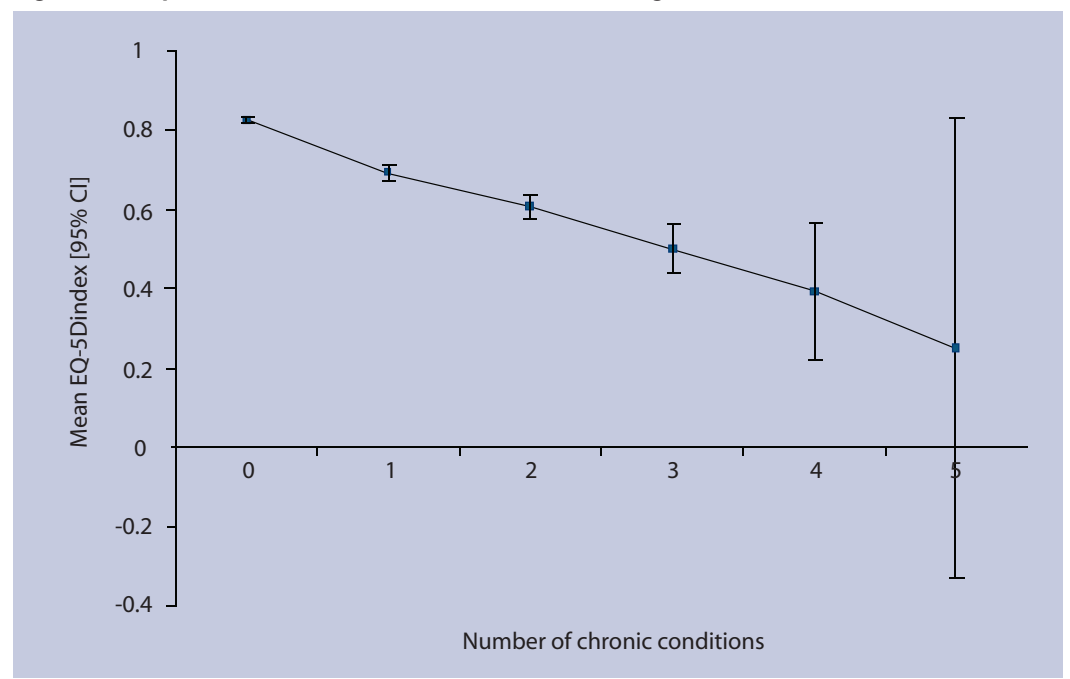

Figure 2. Graph to show mean EQ-5D with increasing number of chronic conditions.

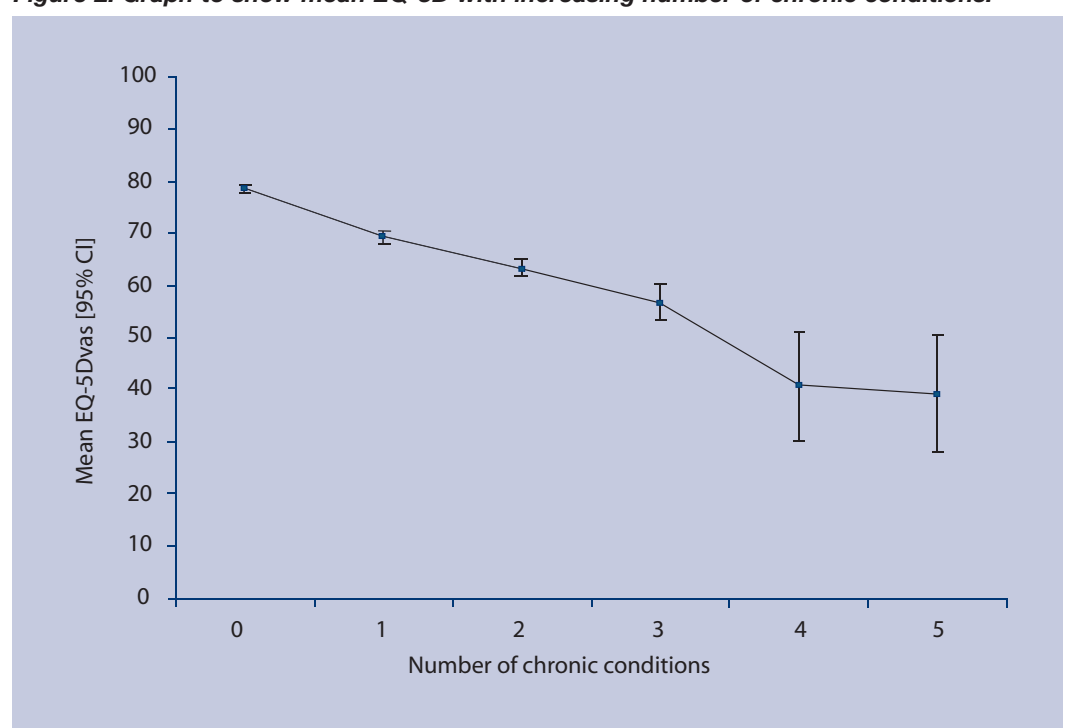


Table 5. Coefficients and significance levels of factors included in the regression model to adjust for confounding factors.

\begin{tabular}{lcccc} 
& $\begin{array}{c}\text { EQ-5Dindex coefficient } \\
\text { (adjusted } R^{2}=0.161,\end{array}$ & $\begin{array}{r}\text { EQ-5D } \text { vas coefficient } \\
\text { (adjusted } R^{2}=0.233,\end{array}$ & \\
& $P<0.001)$ & $P$-value & $P<0.001)$ & $P$-value \\
\hline Constant & 0.987 & $<0.001$ & 86.918 & $<0.001$ \\
\hline Number of chronic diseases & -0.079 & $<0.001$ & -5.914 & $<0.001$ \\
\hline Age (per year) & -0.003 & $<0.001$ & -0.174 & $<0.001$ \\
\hline Smoker & -0.086 & $<0.001$ & -6.363 & $<0.001$ \\
\hline Higher education & 0.033 & 0.001 & 2.156 & 0.002 \\
\hline
\end{tabular}

nervousness about the consequences in use of medical records leading to a decision to opt out. Overall, the analysis of this group suggests minimal impact on the present study by those who opted out. The small differences could mean that older, less educated, and anxious or depressed patients are slightly less well represented within the study data, causing a small overestimate of the HRQoL values, since all these groups were shown to be more likely to have a lower HRQoL, both here and in previous studies. $^{27,28}$

The corroboration of previously reported correlations regarding age,,$^{25,27}$ sex, ${ }^{29-32}$ smoking status, ${ }^{28,29}$ and higher education ${ }^{33}$ are important not only to back up previous research, but also to validate the ability of the present results to represent the general population sample. However, although the differences are significant, the effect sizes are small and must be viewed within the context of the minimal important differences for $E Q-5 D_{\text {index }}$ and $E Q-5 D_{\text {vas, }}$ which are as yet not fully determined.

\section{Comparison with existing literature}

The finding of significant difference between those who had a higher education compared to those who did not is not consistently demonstrated. While the population of the present study was taken from an area in South Manchester designated as deprived, ${ }^{30}$ which might be thought to maximise any potential difference, it is worth noting that previous studies in the same area of Manchester have shown mixed effects. ${ }^{31}$ Studies elsewhere, however, have supported this finding; in an 8-year longitudinal study in Chicago, US, Browning et al found that when income and education were examined, HRQoL improved in relation to reported improvement in education and income. ${ }^{32}$ Browning, et al did not, however, find an association between unemployment and poor HRQoL. ${ }^{32}$ This mixed effect might be somewhat explained by the presence of higher education being tied up with other confounding factors; such as financial status, background, or available resources. This seems to be supported by the present study results following regression analysis.

The only factor that lost significance following regression was sex. Since this study had no upper age limit, including a patient aged 100 years old, this may be because the apparent sex difference was in fact an age difference caused by the increased life expectancy of women.

The $E Q-5 D_{\text {index }}$ dimensions of mobility, self-care, usual activities, pain/discomfort, and anxiety/depression all showed a consistent negative relationship with increasing number of chronic conditions, explaining the observed trend in EQ-5Dindex. Each extra condition has an impact on a patient's functions independent of other conditions, but causes a cumulative effect on EQ-5Dindex.

Previous papers have found that HRQoL is closely linked to physical ability ${ }^{33,34}$ and depression. ${ }^{35}$ This study's breakdown of the EQ-5D dimensions supports these claims but finds their impact to be roughly equal, again supporting calls to treat individuals holistically.

\section{Implications for future research and clinical practice}

Despite the widespread use of the EQ-5Dindex by NICE to aid economic decision making in the UK, the impact of multiple chronic conditions is frequently not considered. This study provides evidence that comorbidity is an important covariate of HRQoL as measured by the EQ-5D. However, it does not distinguish between the different combinations of chronic conditions and is naturally weighted towards those that are more common (for example,

Table 6. Responders reporting any problems on EQ-5D dimension questions by number of chronic diseases.

\begin{tabular}{lccccccc} 
& \multicolumn{9}{c}{ Number of chronic diseases, \% $(n)$} & $\begin{array}{c}P \text {-value } \\
\text { for trend }\end{array}$ \\
\cline { 2 - 7 } Dimension & 0 & 1 & 2 & 3 & 4 & 5 & $<0.001$ \\
\hline Mobility & $17.9(514)$ & $43.4(509)$ & $63.1(317)$ & $76.1(121)$ & $86.7(13)$ & $100(4)$ & $<0.001$ \\
\hline Self-care & $6.7(191)$ & $17.9(206)$ & $24.7(119)$ & $36.1(56)$ & $46.7(7)$ & $100(4)$ & $<0.001$ \\
\hline Usual activities & $19.7(566)$ & $40.7(479)$ & $58.2(287)$ & $71.3(112)$ & $86.7(13)$ & $100(4)$ & $<0.001$ \\
\hline Pain/discomfort & $35.8(1024)$ & $60.2(701)$ & $74.1(360)$ & $80.9(131)$ & $73.3(11)$ & $100(4)$ & $<0.001$ \\
\hline Anxiety/depression & $31.1(888)$ & $39.6(458)$ & $44.8(217)$ & $45.2(71)$ & $60.0(9)$ & $75.0(3)$ & $<0.001$ \\
\hline
\end{tabular}


hypertension and asthma). Is it worse to have two difficult-to-treat, severely disabling diseases or four milder conditions that can be better controlled? Which diseases are worse in combination? It is known that models of health promotion, specifically for those with long-term disabilities have recognised the importance of the physical, cultural, and economic environment. ${ }^{36}$ So what are the effects of the other confounding factors such as social support, educational background, and economic status? In addition, combinations and duration of conditions, including co-existing acute conditions, need to be considered..$^{25}$ It is hoped that in so doing, an increasingly holistic approach to patient care and equitable resource allocation decisions can be made.

\section{Funding body}

Funding to conduct the analyses presented here was provided by the Small Research Grants Scheme of Manchester PCT. The WYCAP surveys were funded by grants from the NHS Executive (RDO/28/1/01), Allen and Hanbury's, Manchester Airport, GlaxoSmithKline, and Astra Zeneca. None of the funding bodies had any involvement in the data collection, analysis, or interpretation, the preparation of manuscripts or the decision to submit for publication

\section{Ethical approval}

Ethical approval for the 1999 survey was obtained from the Local Research Ethics Committee. The 2001 and 2004 surveys were approved by South Manchester Local Research Ethics Committee and Oldham Local Research Ethics Committee respectively

\section{Competing interests}

Isobel TM Heyworth has no competing interests to declare. Mary $\mathrm{F}$ Linehan has received travel grants from GSK. Michelle $L$ Hazell has received a fee from Boehringer Ingelheim for speaking and travel grants from GSK, Boehringer Ingelheim and MSD. Timothy L Frank has received fees for speaking from GSK, Boehringer Ingelheim, Schering Plough, Pfizer, and Astra Zeneca; funds for research from GSK, Boehringer Ingelheim, MSD and Schering Plough; funds for consultancy from GSK, Chiesi Pharmaceuticals, and Pharmacia, and travel grants from GSK, Boehringer Ingelheim, Astra Zeneca, Chiesi Pharmaceuticals, and MSD.

\section{Discuss this article}

Contribute and read comments about this article on the Discussion Forum: http://www.rcgp.org.uk/bjgp-discuss

\section{REFERENCES}

1. Fortin M, Baravo G, Hudon C. Prevalence of multimorbidity among adults seen in family practice. Ann Fam Med 2005; 3(3): 223-228.

2. Hoffman C, Rice D, Sung HY. Persons with chronic conditions: their prevalence and costs. JAMA 1996; 276(18): 1473-1479.

3. Department of Health. The National Service Framework for long-term conditions - good practice guide and examples. London: Department of Health, 2005.

4. Royal College of General Practitioners. Curriculum statement 1. Being a general practitioner. London: RCGP, 2007.

5. Dolan P. Whose preferences count? Med Decis Making 1999; 19(4): 482-486.

6. Bayliss EA, Ellis JL, Steiner JF. Subjective assessments of comorbidity correlate with quality of life health outcomes: initial validation of a comorbidity assessment instrument. Health Qual Life Outcomes 2005; 3: 51 .

7. Dolan P. Valuing health-related quality of life. Issues and controversies. Pharmacoeconomics 1998; 15(2): 119-127.

8. Ng YK. Welfare economics. London: MacMillan, 1992.

9. Fitzpatrick R, Fletcher A, Gore S, et al. Quality of life measures in health care. I: Applications and issues in assessment. BMJ 1992;
305(6861): 1074-1077.

10. Fletcher A, Gore S, Jones D, et al. Quality of life measures in health care. II: Design, analysis, and interpretation. BMJ 1992; 305(6862): $1145-1148$

11. Guyatt GH, Feeny DH, Patrick DL. Measuring health-related quality of life. Ann Intern Med 1993; 118(8): 622-629.

12. Brooks R. EuroQol: the current state of play. Health Policy 1996; 37(1): 53-72.

13. Dolan P. A social tariff for EuroQol: results from a UK general population survey. Discussion paper. York: Centre for Health Economics, 1995.

14. National Institute for Health and Clinical Excellence. Guide to the methods of technology appraisal. London: NICE, 2004.

15. Curtis JR, Patrick DL. The assessment of health status among patients with COPD. Eur Respir J 2003; 21(suppl 41): 36s-45s.

16. Bowker SL, Pohar SL, Johnson JA. A cross-sectional study of health related quality of life deficits in individuals with comorbid diabetes and cancer. Health Qual Life Outcomes 2006; 4: 17.

17. Soriano JB, Visick GT, Muellerova H, et al. Patterns of comorbidities in newly diagnosed COPD and asthma in primary care. Chest 2005; 128(4): 2099-2107.

18. Gudmundsson G, Gislason T, Lindberg E, et al. Mortality in COPD patients discharged from hospital: the role of treatment and comorbidity. Respir Res 2006; 7: 109.

19. Kind P, Hardman G, Macran S. UK population norms for EQ- $5 D$. Discussion paper 172. York: Centre for Health Economics, 1999.

20. Fortin M, Hudon C, Lapointe L, Vanasse A. Multimorbidity is common to family practice. Is it commonly researched? Can Fam Physician 2005; 51: 244-245.

21. Wee $\mathrm{H}$, Cheung Y, Li S, et al. The impact of diabetes mellitus and other chronic medical conditions on health-related quality of life: is the whole greater than the sum of its parts? Health Qual Life Outcomes 2005; 3: 2.

22. Fortin $\mathrm{M}$, Dubois $\mathrm{M}$, Hudon $\mathrm{C}$, et al. Multimorbidity and quality of life: a closer look. Health Qual Life Outcomes 2007; 5: 52.

23. Sin DD, Man SF. Chronic obstructive pulmonary disease: a novel irsk factor for cardiovascular disease. Can J Physiol Pharmacol 2005; 83(1): $8-13$.

24. Sin DD, Wu L, Man SF. The relationship between reduced lung function and cardiovascular mortality: a population-based study and systematic review of the literature. Chest 2005; 127(6): 1952-1959.

25. Burstrom K, Johannesson M, Diderichsen F. Health-related quality of life by disease and socio-economic group in the general population in Sweden. Health Policy 2001; 55(1): 51-69.

26. Fortin M, Lapointe L, Hudon C, et al. Multimorbidity and quality of life in primary care: a systematic review. Health Qual Life Outcomes 2004; $2: 51$.

27. Leplege A, Ecosse E, Pouchot J, et al. Le questionnaire MOS SF-36. Manuel de l'utilisation et guide d'interpretation des scores. Paris: Estem, 2001.

28. Tillman M, Silcock J. A comparison of smokers' and ex-smokers' health realted quality of life. J Public Health Med 1997; 19(3): 268-273.

29. Kind P, Dolan P, Gudex C, Williams A. Variations in population health status: results from a United Kingdom national questionnaire survey. BMJ 1998; 316(7133): 736-741.

30. Department of Planning Studies. 1998 Local census ward comparison. Manchester: Manchester City Council, 2000

31. Hazell M, Morris J, Frank P, Frank T. Temporal change in health related quality of life. A longitudinal study in general practice 1999-2004. Br J Gen Pract 2009: In press.

32. Browning C, Cagney K, Wen M. Explaining variation in health status across space and time: implications for racial and ethnic disparities in self-rated health. Soc Sci Med 2003; 57(7): 1221-1235.

33. Lorraine PJ, Hammock RL, Blanton JM. Predictors of self-rated health status among Texas residents. Prev Chronic Disease 2005; 2(4): A12.

34. Kadam UT, Croft PR, North Stafford GP Consortium Group. Clinical multimorbidity and physical function in older adults: a record and health status linkage study in general practice. Fam Pract 2007; 24(5): 412-419.

35. Patrick DL, Kinne S, Engelberg RA, Pearlman RA. Functional status and perceived quality of life in adults with and without chronic conditions. J Clin Epidemiol 2000; 53(8): 779-785.

36. Patrick DL. Rethinking prevention for people with disabilities. Part 1: a conceptual model for promoting health. Am J Health Promot 1997; 11(4): 257-260. 